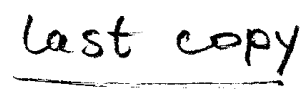

J. Child Psychol. Psychiat. Vol. 24, No. 4, pp. 613-620, 1983.

\title{
AN ISLET OF ABILITY IN AUTISTIC GHILDREN: A RESEARCH NOTE
}

\author{
AmitTa ShaH* and UTA Frith† \\ *MRC Social Psychiatry Unit, London and TMRC Developmental \\ Psychology Unit, London
}

\section{INTRODUCTION}

THE UNEven distribution of cognitive skills in autistic children is a well-documented phenomenon, and is reflected consistently in their pattern of scores on standardized intelligence tests. One area in which classically autistic children of all levels of ability seem to perform particularly well concerns visuo-spatial skills. Lockyer and Rutter (1970), Bartak et al. (1975), Wurst (1976) and Tymchuk et al. (1977) have all analysed profiles of WISC or WAIS test performance and have consistently shown pronounced peaks on the Block Design and Object Assembly subtests. Both these tests have a high loading on a space-performance or perceptual-organization factor (Maxwell, 1959; Cohen, 1959). In all these studies the autistic children performed better on visuo-spatial tasks than their controls matched on overall IQ.

Hermelin and O'Connor (1970) and O'Connor and Hermelin (1978), by studying cognitive strategies as opposed to cognitive levels, added a new dimension to the question of visuo-spatial ability. They found that autistic children show a preference for processing material spatially rather than temporally and that they perform better on tasks requiring the use of spatial cues or codes.

Remarkable visuo-spatial skill in autistic children is apparent also in clinical observations that have, as yet, not been studied experimentally. One example is the commonly reported tendency to notice minute details and to react to very small changes in their surroundings (Wing, 1976). Similarly, the behaviour that Kanner (1943) termed 'insistence on sameness' often refers to concern with the exact spatial arrangements of objects and is manifested by attention to small details rather than overall similarity. Another example is the children's ability to spot missing objects, such as a tiny tablet dropped on a multi-coloured carpet. Often, what is striking is the quickness with which they are able to locate things on which adults have given up searching. High visuo-spatial skills are reflected in their choice of elaborate and repetitive obsessional activities which often involve precise arrangements of objects in space. Furthermore, these skilful activities can be found in autistic children who show marked retardation in all other areas of function. An extreme example is the

Requests for reprints to: Mrs. Amitta Shah, MRC Social Psychiatry Unit, Institute of Psychiatry, De Crespigny Park, London SE5 8AF.

Accepted manuscript received 2 March 1982 
case of Nadia (Selfe, 1977) who, at a very young age, produced drawings of exceptional quality.

These visuo-spatial skills are usually below the level appropriate for chronological age. Whether they can be regarded as 'special' or 'splinter' skills is a matter of debate, and some believe that what are usually called islets of ability "are in reality patches of behaviour where the retardation is less severe"' (Prior, 1979).

The aim of the present study was to explore the relationship between visuo-spatial skills and the ability to attend to perceptual detail. The Children's Embedded Figures Test (CEFT), developed by Karp and Konstadt (Witkin et al., 1971) to study field dependence-field independence, seemed to be well-suited for the purpose. Factor analytic studies (Vernon, 1972; Hyde et al., 1975; McGee, 1979) have indicated that tests of spatial abilities and field dependence-field independence emerge together in a factor similar in description to the spatial orientation factor. Thus the CEFT can be considered to reflect spatial ability as well as the ability to locate targets in potentially confusing backgrounds.

In the light of the evidence reviewed above, autistic children would be expected to perform well on this test compared to MA- and CA-matched mentally retarded and MA-matched normal children.

\section{METHOD}

\section{Subjects}

Subjects consisted of 20 autistic, 20 normal and 20 mildly mentally retarded non-autistic children (Table 1). Within each group there were 15 boys and 5 girls. The male/female proportion was the same across groups since spatial ability is known to be biased in favour of males (Maccoby and Jacklin, 1975). The three groups of children were matched on the basis of mental age estimated from their performance on the Raven's Coloured Progressive Matrices (Raven, 1963). Autistic children are known to perform well on this test (Bartak et al., 1975). This is especially important when looking for a potential islet of ability, as a low estimate of mental age, which may be obtained on a verbal test, might give rise to a false impression of superior performance on a spatial task.

TABLE 1. SUBJECTS

\begin{tabular}{lrcc}
\hline & \multicolumn{3}{c}{ Groups } \\
& Autistic & Mentally retarded & Normal \\
\hline Mean chronological age, yr & 13.30 & 12.80 & 9.30 \\
Standard deviation, yr & 3.53 & 2.07 & 1.36 \\
Mean mental age, yr & 9.60 & 9.56 & 9.45 \\
Standard deviation, yr & 1.42 & 1.42 & 1.30 \\
\hline
\end{tabular}

The autistic children were all from a special school and had been diagnosed by experienced psychiatrists. They all showed abnormalities in social interaction, delayed and abnormal speech development, ritualistic and stereotypic behaviour and in some an insistence on sameness. They ranged in chronological age from 8 to $18 \mathrm{yr}$, with a mean age of $13.3 \mathrm{yr}$. Their mental age, according to the Raven's Coloured Matrices, ranged from 6.6 to $11.3 \mathrm{yr}$, with a mean age of $9.6 \mathrm{yr}$. This roughly corresponds to IQs in the range of 50-70. 
The control group of mildly mentally retarded non-autistic children were from a local special school for this type of children. They were reported to have IQs between 50 and 70 . The children in this group were selected according to their performance on the Raven's Matrices so that the group's MA and CA were both comparable to the MA and CA of the autistic group.

The control group of normal children was drawn from a local primary school. This group only consisted of children who were chosen by their teachers as being 'average performers' and whose performance on the Raven's Matrices was around the 50th percentile level for their chronological age. These children were comparable in mental age to that of the autistic and retarded groups but were considerably younger.

\section{Material}

The test material from the Children's Embedded Figures Test (Witkin et al., 1971) was used. There were two cut-out cardboard models, one of a triangle ('Tent') and another of a triangle attached to the top of the left part of a rectangle ('House'). There were also 11 complex figures which had the simple form 'Tent' and 14 which had the 'House' embedded in them. Two examples are shown in Fig. 1. There were 3 additional practice figures.

\section{Procedure}

The CEFT standard training and testing procedure was followed except for one important change: during training all children were encouraged to place the cut-out target shapes on top of the hidden shapes. This was done in order to leave no ambiguity in task understanding. The cut-out target

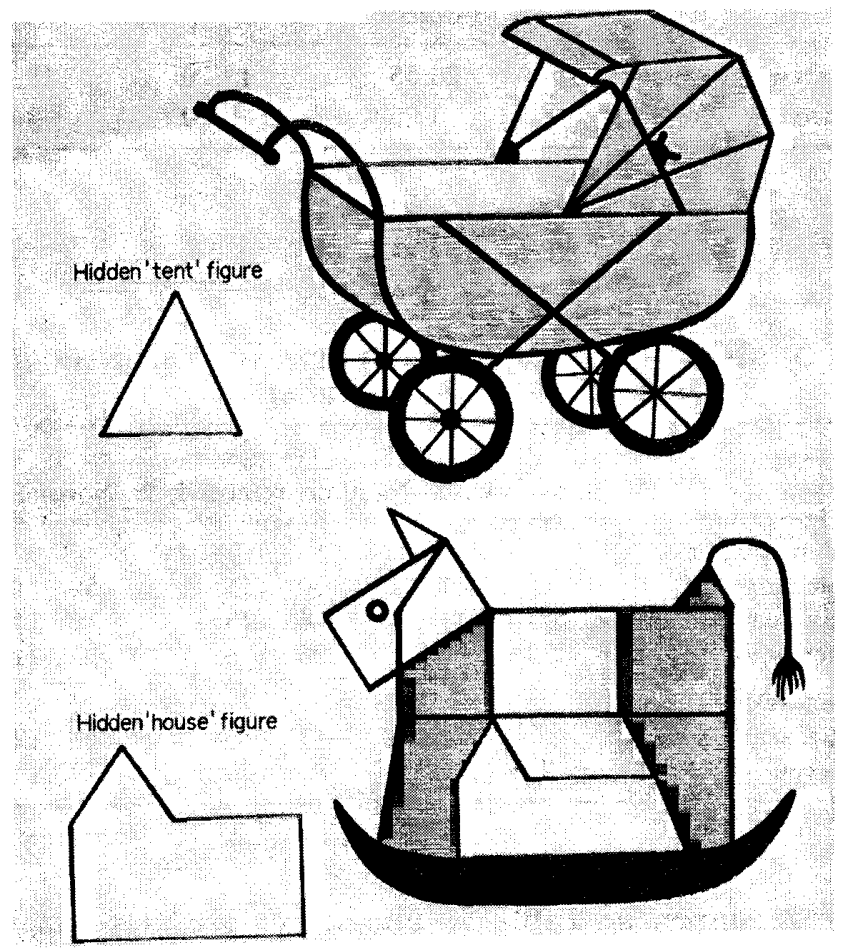

FIG. 1. Examples of complex figures. Reproduced from the Children's Embedded Figures Test (Karp and Konstadt, 1971) by special permission from Consulting Psychologists Press, Inc., Palo Alto, CA. 
shapes continued to be present during the test. Therefore, for his responses the child could either point to the target figure or could place the cut-out form over his chosen location. Three strategies could be readily observed and distinguished objectively: (a) where the child seemed to see the target figure right away without any obvious search (immediate response); (b) where the child pointed to the target figure after some deliberation without using the cut-out shape (visual search); (c) where the child did use the cut-out shape for his search, either by sliding or repeated placements (concrete search).

\section{RESULTS}

Accuracy scores are shown in Table 2. Analysis of variance showed that there was a significant difference between the scores of the three groups $(F=28.18$; d.f. $=2.54$; $P<0.001)$. This was due to the autistic children having significantly higher scores than either the normal children $(t=3.19 ; P<0.01)$ or the retarded children $(t=7.04 ; P<0.01)$. There was no significant difference between the two control groups. For all groups equally, boys tended to have higher scores than girls, but this difference just failed to reach significance $(F=3.70 ;$ d.f. $=1,54 ; P=0.06)$.

TABle 2. MEAN AND STANDARD DEVIATIONS OF ACCURACY SCORES

\begin{tabular}{|c|c|c|c|}
\hline & Autistic & $\begin{array}{c}\text { Groups } \\
\text { Mentally retarded }\end{array}$ & Normal \\
\hline Mean accuracy $(\max .=25)$ & 20.55 & 13.70 & 15.70 \\
\hline Standard deviation & 3.25 & 2.89 & 3.06 \\
\hline
\end{tabular}

TABle 3. MEAN PERCENTAge of EACH STRATEgy USED (STANDARD DEVIATION IN BRACKETS)

\begin{tabular}{lrlrrrr}
\hline & \multicolumn{7}{c}{$\begin{array}{c}\text { Groups } \\
\text { Autistic, \% }\end{array}$ Mentally retarded, \% } & Normal, \% \\
\hline $\begin{array}{l}\text { Correct responses } \\
\text { Immediate }\end{array}$ & 63 & $(16)$ & 60 & $(15)$ & 52 & $(16)$ \\
$\quad \begin{array}{l}\text { Visual search } \\
\text { Concrete search }\end{array}$ & 7 & $(11)$ & 4 & $(5)$ & 15 & $(11)$ \\
$\begin{array}{l}\text { Incorrect responses } \\
\quad \text { Visual search }\end{array}$ & 30 & $(18)$ & 36 & $(16)$ & 33 & $(19)$ \\
$\quad$ Concrete search & 7 & $(13)$ & 11 & $(15)$ & 16 & $(21)$ \\
\hline
\end{tabular}

Strategy scores are shown in Table 3 . The scores are percentages in order to eliminate the differences in performance level. Non-parametric tests were used for analysis whenever the distribution of scores necessitated this. Analysis of variance on strategies used for correct responses showed that the three groups differed with 
regard to the proportions of immediate responses, but this difference did not reach significance $(F=2.89$; d.f. $=2,57 ; P=0.06)$. Autistic children tended to use the immediate strategy more often than the control children. No significant group difference was found for concrete search. However, there was a significant group difference with regard to visual search $[H=12.97$; d.f. $=2 ; P<0.01$ on the Omnibus Test of unified analysis of variance by ranks (Meddis, 1980)]. Nineteen out of 20 normal children used visual search at least once compared to only 10 out of 20 autistic children and 9 out of 20 retarded children.

In the case of incorrect responses the immediate strategy was hardly ever used, and therefore a separate category was not warranted for analysis. There was a small proportion of incorrect responses (less than $5 \%$ ) in all groups which could not be clearly assigned to any category. The groups differed significantly in their use of the visual search strategy $(H=7.06 ;$ d.f. $=2 ; P<0.05)$. Post hoc comparison indicated that the autistic group used this strategy significantly less often than both the other groups $(z=2.56 ; P<0.01)$. There was also a significant group difference on the use of concrete search on incorrect responses $(H=6.41$; d.f. $=2 ; P<0.05)$. This was due to the normal group using this strategy less often than the other groups $(z=2.27$; $P<0.05)$.

\section{DISCUSSION}

The autistic children performed significantly better on the embedded figures task than either the normal or retarded control group. The use of an appropriate control group of mentally retarded non-autistic children enables one to associate these findings specifically with autism.

The overall results of the present study can be compared, with caution, with the standardization norms provided for CEFT (Witkin et al., 1971). Although our procedure differed somewhat from the standard one, the normal control group achieved a score commensurate with the average score of their peer group in the original sample. A score of 16.4 (S.D. = 5.5) was average for age 9-10 yr in that sample, while the normal children in the present study achieved a mean score of 15.7. The retarded children achieved a mean score of 13.7 , still commensurate with normal performance at their mental age of $9 \mathrm{yr}$. In contrast, the autistic children, with a score of 20.5, performed at least as well as the oldest group in the standardization sample, aged $11-12 \mathrm{yr}$, whose mean score was 18.0 (S.D. $=5.1$ ). This suggests strongly that the performance of the autistic children on the embedded figures test approximates the level expected from their chronological age. This is surprising since their performance on more general visuo-spatial tasks such as the Block Design and Object Assembly subtests of the WISC, although better than their performance on verbal tests, is usually below their chronological age level. This discrepancy needs an explanation.

One explanation is provided by the hypothesis that autistic children show uneven ability on two factors involved in spatial skills-specifically, they have good orientation ability but poor visualization ability. Orientation ability involves the comprehension of the arrangement of elements within a stimulus pattern and, as mentioned earlier, is closely relevant to finding embedded figures. Visualization 
involves the ability to mentally manipulate, rotate, twist or invert a pictorially presented stimulus object (McGee, 1979). This ability cannot be considered important for the embedded figures task as the hidden target figure is never rotated or reversed. Block Design and Object Assembly tasks require both orientation and visualization abilities. On these tasks it is often necessary to mentally rotate the constituent elements in order to see how a given figure may be constructed. If autistic children's visualization ability was poor while their orientation skill was good, it would follow that their performance on these tasks was somewhat worse than on embedded figures.

In the present study some tentative evidence for poor visualization is shown by the fact that autistic children very rarely used a strategy of purely visual search. Instead, unless they found the hidden figure immediately, they searched by means of the cut-out shape. This was in significant contrast to the normal control group. The contrast to the retarded group was less clear-cut as it only appeared with incorrect responses. With correct responses autistic children again rarely showed the visual search strategy, but neither did the retarded children.

The notion that autistic children may have poor visualization ability is also suggested by experimental findings reported by O'Connor and Hermelin (1975). They found that on spatial tasks which could only be solved by reference to and manipulation of an internal visual representation, autistic children performed poorly. Hermelin (1978) proposed that autistic children may lack the ability to form or manipulate mental images. A similar conclusion was drawn by Hammes and Langdell (1981) on the basis of experiments on autistic children's imitation ability.

In addition to their superior accuracy; there was also a tendency for autistic children to spot the embedded figures more quickly than the other groups. This quickness is extremely reminiscent of clinical impressions of a particular rapid style of locating things and their immediate discovery of minute changes in a familiar lay-out. Good orientation ability alone is probably not a sufficient explanation for this phenomenon. In order to find the hidden figure disembedding is necessary, as was shown by Gottschaldt (1926), from whose original study the embedded figures test has been derived. He concluded that the separateness of details disappears due to the "forming predominance of the whole". The task of finding the embedded figures consists of breaking down this given whole.

With the present test figures an effort is needed to resist the tendency to see only the forcefully created gestalt which in itself is a meaningful picture (Koffka, 1935). That the autistic children actually perceived the overall meaning was indicated by their ability to name the complex figures, e.g. 'man', 'dog', 'pram'. Perhaps they were able to locate the target figure so easily because the overall meaning of the complex figure (or the embedding context) was not very relevant or dominant for them. In other words, they experienced less capture by meaning. This hypothesis is consistent with the cognitive-deficit theory proposed by Hermelin and O'Connor (1970) which implies that autistic children hold information in a relatively 'raw' or unprocessed form due to a central deficiency in the processing of information. These conclusions are based on experiments (summarized in Hermelin and Frith, 1971; Hermelin, 1976) which show consistently that on memory recall tasks, autistic children do not benefit from being presented with meaningful or rule-governed 
stimuli as opposed to nonsense or random ones. In contrast, normal and retarded non-autistic children always perform better on meaningful presentations. For the hidden figures this tendency to use meaningful content is actually detrimental to the task in hand. Therefore, one should expect that autistic children perform better, unhindered as they are by the dominance of the overall meaning. The ability to find embedded figures easily is analogous to the ability to remember many items of randomly arranged sequences of words or colours (Frith, 1970a, b). The present finding, therefore, extends the theory of cognitive deficit from sequential to simultaneous tasks. However, to succeed at finding embedded figures, one also needs spatial ability. Since autistic children have both the cognitive deficit specified and high spatial orientation ability, their performance on the CEFT is at a level which enables one to regard it as a true islet of ability.

Finally, although we did not use the embedded figures test (EFT) in order to assess field dependence-field independence as a dimension of personality, it is intriguing that studies have suggested an association between field dependence, i.e. low EFT scores, sensitivity to social cues in contrast to field independence, i.e. high EFT scores, and low sensitivity to social cues (Witkin et al., 1971; Kagan and Kogan, 1970). In view of the fact that social impairment is a unique distinguishing characteristic of autistic children, it is interesting that they did, in fact, achieve extremely high scores typical of high field independence.

\section{SUMMARY}

An aspect of cognitive functioning in autistic children was investigated by comparing their performance on the Children's Embedded Figures Test with that of MA-matched normal and MA- and CA-matched mentally retarded non-autistic children. The autistic children were significantly more competent at this task than either group of control children, and also showed qualitatively different strategies. Since the performance of the autistic children was better than predicted from MA and commensurate with CA, it can be regarded as an islet of ability. This finding is discussed in terms of orientation and visualization factors involved in visuo-spatial abilities and is also related to cognitive deficit.

Acknowledgements-This report is based on a master's thesis completed by the first author at the University of Surrey, under the supervision of the second author. We are greatly indebted to the children who took part in the study and to the headteachers and teachers of the following schools: Helen Allison School for Autistic Children, Gravesend; Medway School for ESN(M) Children, Tooting; Woodmansterne School, Streatham. We also wish to thank Dr. Lorna Wing for her valuable suggestions on several drafts of this manuscript.

\section{REFERENCES}

BARTAK, L., RUtTer, M. and CoX, A. (1975) A comparative study of infantile autism and specific developmental receptive language disorder: I. The children. Br. J. Psychiat. 126, 127-145.

CoHEN, J. (1959) The factorial structure of the WISC at ages 7-6, 10-16 and 13-6. J. consult. Psychol. 23, 285-299. 
FRITH, U. (1970a) Studies in pattern detection. I. Immediate recall of auditory sequences. J. abnorm. Psychol. 76, 413-420.

FRITH, U. (1970b) Studies in pattern detection. II. Reproduction and production of color sequences. J. exp. Child Psychol. 10, 120-135.

FRITH, U. and HERMELIN, B. (1969) The role of visual and motor cues for normal, subnormal and autistic children. J. Child Psychol. Psychiat. 10, 153-163.

GotTschaldT, K. (1926) Uber den Einfluss der Erfahrung auf die Wahrnehmung von Figuren. Psychol. forsch. 8, 261-317.

Hammes, J. G. W. and Langdell, T. (1981) Precursors of symbol formation and childhood autism. J. Aut. dev. Disord. 11, 331-346.

Hermelin, B. (1976) Coding and the sense modalities. In Early Childhood Autism (Edited by WING, L.), 2nd Edn, pp. 135-168. Pergamon Press, Oxford.

HERMELIN, B. (1978) Images and language. In Autism: A Reappraisal of Concepts and Treatment (Edited by Rutter, M. and SchOPLeR, E.), pp. 141-154. Plenum Press, New York.

Hermelin, B. and Frith, U. (1971) Psychological studies of childhood autism. Can autistic children make sense of what they see and hear? J. spec. Educ. 5, 1107-1117.

Hermelin, B. and O'Connor, N. (1970) Psychological Experiments with Autistic Children. Pergamon Press, Oxford.

Hermelin, B. and O'ConNoR, N. (1971) Spatial coding in normal, autistic and blind children. Percept. Motor Skills 33, 127-132.

HYDE, J. S., GEIRINGER, E. and YeN, W. (1975) On the empirical relation between spatial ability and sex differences in other aspects of cognitive performance. Multivariate Behav. Res. 10, 289-301.

KAGAN, J. and KOGAN, N. (1970) Individuality and cognitive performance. In Carmichael's Manual of Child Psychology (Edited by MUSSEN, C. H.), Vol. 1, 3rd Edn, pp. 1273-1365. John Wiley, New York.

KanNer, L. (1943) Autistic disturbance of affective contact. Nerv. Child 2, 217-250.

KoffKA, K. (1935) Principles of Gestalt Psychology. Harcourt, Brace, New York.

LOCKYER, L. and RUTTER, M. (1970) A five to fifteen year follow-up study of infantile psychosis. IV. Patterns of cognitive ability. Br. J. soc. clin. Psychol. 9, 152-163.

MAXWELL, A. E. (1959) A factorial analysis of the Wechsler Intelligence Scale for Children. Br. J. educ. Psychol. 29, 237-241.

MaCCOBY, E. E. and JACKLIn, C. N. (1975) The Psychology of Sex Differences. Oxford University Press, London.

MCGeE, M. (1979) Human spatial abilities. Psychometric studies and environmental, genetic, hormonial and neurological influences. Psychol. Bull. 86, 889-918.

MEDDIS, R. (1980) Unified analysis of variance by ranks. Br. J. math. statist. Psychol. 33, 84-98.

O'Connor, N. and Hermelin, B. (1975) Modality-specific spatial coordinates. Percept. Psychophys. $17,2,213-216$.

O'Connor, N. and Hermelin, B. (1978) Seeing and Hearing and Space and Time. Academic Press, London.

PrIOR, M. R. (1979) Cognitive abilities and disabilities in infantile autism: a review. J. abnorm. Child Psychol. 7, 357-380.

Raven, J. C. (1963) Guide to Using the Coloured Progressive Matrices. H. K. Lewis \& Co., London.

Selfe, L. (1977). Nadia: a Case of Extraordinary Drawing Ability in an Autistic Child. Academic Press, London.

TYMchuk, A. J., Simmons, J. Q. and NeAFSEY, S. (1977) Intellectual characteristics of adolescents childhood psychotics with high verbal ability. J. ment. Defic. Res. 21, 133-138.

Vernon, P. E. (1972) The distinctiveness of field independence.J. Personality 40, 366-391.

WER THEIMER, M. (1923) Untersychungen zur lehre von der gestalt. II. Psychol. Forsch. 4, 301-350.

WING, L. (1976) Diagnosis, clinical description and prognosis. In Early Childhood Autism (Edited by WING, L.), 2nd Edn, pp. 15-48. Pergamon Press, Oxford.

Witkin, H. A., Oltman, P. K., RAskin, E. and KARP, S. (1971) A Manual for the Embedded Figures Test. Consulting Psychologists Press, California.

Wurst, E. (1976) Autismus. Verlat Hans Huber, Bern. 